\title{
0 turismo como um sistema complexo: sociabilidades, comunicações e desafios metodológicos
}

Tourism as a complex system: sociabilities, communications and methodological challenges

El turismo como un sistema complejo: sociabilidades, comunicaciones y desafíos metodológicos

http://dx.doi.org/10.18472/cvt.18n1.2018.1481

Thaís Costa da Silva < thais_unirio@yahoo.com.br >

Universidade do Estado do Rio de Janeiro (UERJ), Rio de Janeiro, RJ, Brasil

CRONOLOGIA DO PROCESSO EDITORIAL

Recebimento do artigo: 02-set-2017

Aceite: 15 -jan-2018

FORMATO PARA CITAÇÃO DESTE ARTIGO

SILVA, T. C. da. O turismo como um sistema complexo: sociabilidades, comunicações e desafios metodológicos. Caderno Virtual de Turismo. Dossiê Temático: II Seminário Nacional de Turismo e Cultura da Fundação Casa de Rui Barbosa. Rio de Janeiro, v. 18, n. 1, p. 53-65, abr. 2018.

REALIZAÇÃO

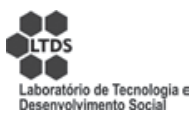

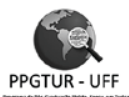

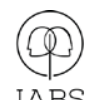

APOIO INSTITUCIONAL

EDIÇÃO

PATROCÍNIO

COPPE

UFR]

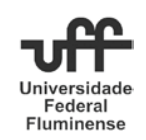

EDITORA 


\section{RESUMO}

Este ensaio busca provocar reflexões sobre como vem sendo interpretado e representado o sistema de turismo em toda a sua complexidade, sob as luzes dos pensamentos moderno e contemporâneo. Ressaltam-se os processos culturais, de sociabilidade e comunicativos entre os diversos atores envolvidos, bem como sua imprevisibilidade, historicidade e não linearidade, características intrínsecas aos sistemas complexos. $\mathrm{O}$ trabalho também discute os desafios metodológicos e epistemológicos que pesquisadores da área enfrentam, e sugere que as investigações adotem uma abordagem transdisciplinar e multimetodológica.

Palavras-chave: Sistemas complexos. Sistemas de turismo. Transdisciplinaridade.

\section{ABSTRACT}

This essay seeks to instigate reflections about how the tourism system has been interpreted and represented in all its complexity, under the light of modern and contemporary thoughts. The cultural, social and communication processes among the actors involved, as well as their unpredictability, historicity and nonlinearity, characteristics of complex systems, are highlighted. The paper also discusses the methodological and epistemological challenges that researchers of the field face and suggests that the investigations take a multidisciplinary and multi methodological approach.

Keywords: Complex systems. Tourism System. Transdisciplinarity.

\section{RESUMEN}

Este ensayo busca provocar reflexiones sobre cómo viene siendo interpretado y representado el sistema del turismo en toda su complejidad, bajo las luces de los pensamientos moderno y contemporáneo. Se resaltan los processos culturales, de sociabilidad y comunicación entre los diversos actores involucrados, así como su imprevisibilidad, historicidad y no linealidad, características intrínsecas a los sistemas complejos. El trabajo también discute sobre los desafíos metodológicos y epistemológicos que los investigadores del área enfrentan y sugiere que las investigaciones adopten un enfoque transdisciplinario y multi metodológico.

Palavras clave: Sistemas complejos. Sistemas de turismo. Transdisciplinariedad. 


\section{ENTRE FLUXOS E ARTICULAÇÕES}

Não são poucas as reportagens sobre o assunto em pequenos e grandes veículos de informação e comunicação. A intensificação da atividade turística em Barcelona, assim como em muitos outros lugares do mundo, tem provocado repulsa nos habitantes da cidade. E a plataforma de hospedagem Airbnb é um dos maiores motivos dessa querela.

Sob o lema "Sinta-se como vivesse lá", este se trata de um dos maiores sites que propicia o aluguel por temporada em residências nos mais diversos lugares do mundo. Sua popularidade é tão grande que, em 2016, a empresa ofereceu mais de 20.000 anúncios de hospedagem na cidade espanhola, muitos deles ilegais, segundo reportagem veiculada no jornal El País em 09 de maio de 2017. Essa grande demanda despertou o interesse de empresários que priorizaram esse tipo de negociação à locação para moradores, resultando em um aumento no valor dos aluguéis e a consequente migração dos barceloneses para outras cidades, como Rolnik (2017) e Jorge (2017) evidenciam.

$\mathrm{Na}$ Áustria, a ação de hackers bloqueou as portas de um hotel ao invadirem o sistema de computação conectado às fechaduras eletrônicas, de acordo com reportagem da Folha de São Paulo, em 01 de fevereiro de 2017. A intenção era de solicitar um resgate em bitcoins, uma moeda digital com rastreamento dificultado. Após muitos transtornos causados aos hóspedes, o hotel pagou a quantia solicitada, a fim de solucionar o problema. Esse tipo de crime é uma prática de pirataria moderna muito comum na atualidade e que vem crescendo significativamente.

Conexões entre fatores políticos, econômicos, sociais e culturais engendram em caminhos múltiplos pelos quais o turismo opera. E os diversos atores envolvidos nesse processo, entre sujeitos, instituições, objetos e tecnologias, contribuem para a complexificação desse sistema. As movimentações turísticas massivas influenciam o custo de moradia em Barcelona e se chocam com a legislação local e com o bemestar de seus moradores. A inovação tecnológica, por sua vez, otimiza os processos do hotel austríaco ao mesmo tempo em que é usada como ferramenta para sequestrar e amedrontar seus hóspedes. $\mathrm{O}$ turismo é indissociável dos acontecimentos que o circundam, caracteriza-se por um sistema aberto que sofre influências de agentes internos e externos. E essa complexidade de articulações e variáveis está se tornando cada vez mais evidente na contemporaneidade.

Com a revolução científica, relativismos foram pensados, ressaltando-se a ideia de que o todo é maior que a soma das partes. A ciência passou por um amplo processo de metamorfose, como Prigogine e Stenders (1997) ressaltam. Sistemas lineares são raros em nossa sociedade, ante as inúmeras variações e multiplicidades existentes em sistemas como o do turismo. Por essa razão foi preciso um afastamento de determinismos na ciência.

Nesse contexto, os estudos sobre os sistemas complexos se desenvolveram no século XIX, e analisar a interação entre as partes se tornou prática fundamental nos procedimentos metodológicos sobre esses tipos de sistemas. Régis (2006, p. 154) ressalta que eles são

sensíveis às condições iniciais, isto é, de acordo com as variações que ocorram no estado inicial do sistema, sua evolução se torna imprevisível. São por essa razão sistemas de comportamento caótico, pois mudam de estado sob efeito da ação do tempo.

Sob a égide do processo, todos estão suscetíveis a transformações, e as tecnologias avançadas contribuem substancialmente para acelerar os padrões de mudança dos sistemas (OLIVEIRA, 2003). Dispositivos 
como os smartphones, computadores ou o telefone são capazes de influenciar nossa maneira de interagir e de se comunicar. Os aparatos tecnológicos podem estimular diferentes formas dos indivíduos viajarem ao oferecerem a possibilidade de organização de suas viagens por meio de um aplicativo, por exemplo. E são múltiplas as formas de uso e de apropriação desses aparatos, de acordo com as particularidades de cada pessoa.

Em sistemas complexos são mais notáveis essas diferenças entre os indivíduos, que estão associados ao meio, como defende Simondon (2005). As relações entre eles são entendidas como "potencialidades conectivas, fundamento de uma capacidade imanente de engendrar estruturas, de produzir formas" (OLIVEIRA, 2003, p. 156). Interações de viajantes heterogêneos que se comportam de modos distintos e que estão intrinsecamente relacionados aos ambientes que visitam e que vivem.

E se os elementos desses sistemas possuem um alto grau de articulação entre os atores envolvidos e se o meio influencia as ações dos indivíduos em uma lógica processual, por que então analisar as partes separadamente? Se questões jurídicas e sociais, ou se a tecnologia interferem nas formas de viajar, na gestão de empreendimentos turísticos, ou nas relações entre visitantes e visitados, podemos compreender o turismo como um sistema complexo a ser pensado transdisciplinarmente e em variadas dimensões? $\mathrm{O}$ pensamento científico contemporâneo propõe reflexões como essas, a fim de discutir as ideias difundidas na modernidade trazendo à tona outras percepções e sentidos.

O turismo, desse modo, não se concerne somente à hospedagem ou aos atrativos turísticos de forma isolada. Ele está também difundido nas relações sociais, no comportamento dos indivíduos, nas formas de comunicação entre eles, na apropriação dos territórios e nas múltiplas transformações imbricadas nesses processos.

\section{O TURISMO COMO PRÁTICA SOCIAL}

O termo turismo foi cunhado na Inglaterra somente no século XVII da era moderna, segundo Barretto (2004). Contudo, deslocamentos e encontros entre indivíduos já existem desde os primeiros indícios da humanidade, sendo difícil identificá-los com exatidão. Os deslocamentos que englobam as idas e vindas dos indivíduos são entendidos como viagens, sendo o turismo um conceito que se refere à "existência também de recursos, infraestrutura e superestrutura jurídico-administrativa” (BARRETTO, 2004, p. 44).

Muitos autores divergem sobre o início da atividade turística em razão dos variados indícios e interpretações que se fazem sobre as viagens. Alguns consideram seu histórico por meio da divisão em fases, baseando-se em comportamentos comuns dos viajantes e em fatores sociais, políticos e econômicos.

Lickorish e Jenkins (2000) classificam o turismo em quatro estágios. O período pré-histórico, para os autores, compreendia a era medieval e o início do século XVII, em que se destacam as rodovias romanas que possibilitaram muitas viagens e comunicações na Europa. A fase dos transportes, no século XIX, marcou o período em que os trens e navios a vapor possibilitaram a intensificação dos deslocamentos e quando as viagens em massa se originaram. No período entre guerras, que engloba os anos de 1918 a 1939, houve uma retração do fluxo de turistas em razão das dificuldades econômicas e políticas advindas após a Primeira Grande Guerra. Essa é considerada também a era dos automóveis. Por último, a "decolagem do turismo" representa a última fase que se estende até os dias atuais, destacando-se a revolução tecnológica. 
Já Barbosa (2002) historiciza os acontecimentos que originaram o turismo inicialmente com o período dos primeiros deslocamentos humanos. Movimentos que ocorreram na Idade Antiga, entre os povos romanos, gregos e fenícios, e na Idade Média, com o nomadismo e as peregrinações. O Grand Tour marca então um segundo momento, com a organização de viagens culturais e educacionais realizadas por jovens livres e ricos do século XVI ao XVIII. "Esses jovens deveriam percorrer o mundo, ver como ele era governado e se preparar para ser um membro da classe dominante" (BARBOSA, 2002, p. 31-32). O surgimento e valorização dos balneários marítimos ressaltam uma terceira fase, que reverbera na seguinte que é a da modernização dos transportes, com o uso de trens, aviões e navios e das férias remuneradas.

Entre as muitas fases citadas pelos autores, as que englobam a era moderna merecem destaque. "O turismo moderno havia, de fato, se estabelecido com seus principais elementos até a deflagração da Primeira Guerra Mundial, em 1914" (LICKORISH; JENKINS, 2000, p. 34). É nesse momento que o termo turismo é conceituado e é quando sua prática se intensifica, muito balizada pelo sistema econômico capitalista que se fortalecia e no desenvolvimento dos transportes e dos meios de comunicação.

O processo de urbanização e a evolução dos transportes facilitaram os grandes deslocamentos, sobretudo com a criação das estradas e com o surgimento das ferrovias. As novas tecnologias de comunicação contribuíram para o maior acesso às informações sobre os destinos e para a maior interação entre os indivíduos, mesmo fora de seu entorno habitual. E a conquista de direitos trabalhistas propiciou o aumento do tempo livre que poderia ser utilizado em atividades de lazer e turismo, em razão da redução gradativa das horas de trabalho e das férias remuneradas.

O rápido crescimento do fluxo de turistas ao redor do mundo, especialmente após a II Guerra Mundial, acompanhou movimentos políticos, econômicos e culturais que se delineavam. Em razão da crescente circulação de indivíduos nas cidades, hotéis foram construídos para suprir a demanda desses viajantes. Entre as diversas motivações, as pessoas buscavam praticar o turismo como forma de lazer. Dumazedier (1974, p. 55) aponta que essa prática resulta de dois movimentos simultâneos:

a) o progresso científico-técnico apoiado pelos movimentos sociais libera uma parcela do tempo de trabalho profissional e doméstico; b) a regressão do controle social pelas instituições básicas da sociedade (familiais, socioespirituais e sociopolíticas) permite ocupar o tempo liberado principalmente com atividades de lazer.

Com a valorização do uso do tempo livre para atividades de lazer na modernidade, essa prática se torna um direito social em muitos países, inclusive no Brasil. Dessa forma, iniciativas promovidas pelos governos para garantir esse direito à população envolvem também as atividades turísticas, como o programa Viaja Mais Melhor Idade, do Ministério do Turismo do Brasil, que visa facilitar viagens para idosos por meio de parcerias com empresas privadas.

Nesse cenário, grande parte das viagens era organizada de modo padronizado, por meio de pacotes turísticos elaborados por intermediários, como as agências e operadoras de viagens. Com base nesse fato, Lash e Urry (1987) classificam o turismo moderno como um turismo organizado, relacionando-o com o modo de produção fordista característico do sistema capitalista organizado do século XIX.

Contudo, desde as primeiras excursões coletivas comercializadas por Thomas Cook na Inglaterra moderna de 1841 (JENKINS; LICKORISH, 2000) até os dias atuais, diversas foram as transformações pelas quais o turismo sofreu. Assim como as tecnologias foram fundamentais para o desenvolvimento do turismo em fins do século XVIII, elas também foram essenciais para muitas transformações que se delineiam na contemporaneidade. Os comportamentos dos indivíduos se complexificaram, nem os 
modos de viajar nem as motivações são mais as mesmas. Tudo está em devir, a partir da multiplicidade de acontecimentos, de encontros e afetos dos sujeitos, como Deleuze e Guattarri (1997) enunciaram. E o turismo é parte desse processo.

Os diversos acontecimentos ocorridos ao longo de eras e que se relacionam às práticas turísticas, como são conhecidas na atualidade, traçam então um caminho histórico que aponta continuidades e descontinuidades em ações e comportamentos. Esse então não pode ser considerado um caminho evolutivo, nem mesmo linear. Os fluxos de viajantes crescem e se retraem de acordo com conflitos, investimentos em infraestrutura, por decisões políticas e por disputas de poder.

Impulsionados pelo desejo de compreender melhor o fenômeno por meio de uma visão global de seus elementos e articulações, a sistematização do turismo tem sido pensada por diversos pesquisadores nas últimas décadas. De acordo com Lohmann e Panosso Netto (2016), Raymundo Cuervo é um dos teóricos considerados precursores desse movimento, com a publicação El Turismo como Medio de Comunicación Humana, de 1967. Nesse livro, ele defende que o turismo pode ser entendido como um conjunto bem definido de relacionamentos, serviços e facilidades gerados em razão de movimentos humanos. À luz da teoria geral dos sistemas proposta por Bertalanffy's, o autor enfoca a relação entre o turismo e as práticas sociais, salientando que sua função é a comunicação, resultando em efeitos positivos e negativos na sociedade.

O argumento de Cuervo chama atenção para o fato de que o turismo está associado a outros sistemas e que, por isso, a análise e interpretação de seu funcionamento devem ser feitas em associação a outros fatores. "Ao separar o turismo em um sistema, é importante lembrar que ele é parte de um sistema maior, como o sistema social" (LOHMANN; PANOSSO NETTO, p. 04, 2016)ํ․

Outros autores também se debruçaram sobre esse tema, como Leiper em 1979, enfatizando também os elementos geográficos, os turistas e a indústria de turismo e viagens como partes desse sistema aberto. Já Molina (1997) se destacou como estudioso do turismo na América Latina ao propor um modelo de sistema composto por subsistemas que interagem entre si. No Brasil, Beni (2001) criou o modelo Sistur para esquematizar o turismo, dividindo o sistema em conjuntos de elementos que se interagem interna e externamente com outros sistemas.

Todos os modelos propostos foram fundamentais para se refletir sobre as muitas variáveis e interações intrínsecas ao campo. Seus esquemas são ainda bastante utilizados por pesquisadores e gestores que pensam o turismo, pois englobam elementos fundamentais para o turismo. Contudo, eles ainda apresentam algumas lacunas que precisam ser discutidas a fim de repensar metodologias e teorias para uma melhor compreensão desse fenômeno.

Em razão da complexidade de funcionamento do sistema, as transitoriedades dos atores e de suas interações, a historicidade dos elementos e mesmo as suas invenções não são contempladas com afinco. Isso porque os sistemas complexos são imprevisíveis e delimitar fronteiras por meio de esquemas, ainda que considerem suas interações, é um modo ainda insuficiente para se analisar o campo.

Essas fronteiras em muito se relacionam ao modo de fazer ciência moderno, que defende uma imagem racionalista do mundo em um modelo organicista que é o da teoria geral dos sistemas (TOURAINE, 2002). Nesse sentido, o pensamento científico contemporâneo sugere um estudo que considere essas 
imprevisibilidades e a historicidade dos elementos dos sistemas. Como defende Vaz (1996, p. 133), "historicizar a história implica historicizar o modo como os homens se situam no mundo em relação a tudo o que há e se propõem uma tarefa ao se aperceberem da singularidade de seu presente".

Com a revolução científica, com as mudanças no comportamento do sujeito-consumidor e com a criação das novas tecnologias de comunicação e informação, as formas de se praticar o turismo vêm se pluralizando; cresce o turismo segmentado, flexível e personalizado, baseado no modelo econômico pósfordista, como Lash e Urry (1987) relatam. Movimentos e historicidades que não são contemplados nos modelos baseados na teoria geral dos sistemas e que em muito dialogam se associam às novas tecnologias da comunicação e informação.

\section{DIVERSIFICAÇÕES NAS LÓGICAS DE CONSUMO}

Para decidir sobre qual destino visitar, uma consulta a blogs e sites colaborativos de avaliação de destinos, como o Trip Advisor ou o Yelp. Para comprar um bilhete de transporte aéreo, buscadores como o Google Flights ou o Skyscanner. Para reservar o hotel, agências on-line, como o Booking.com ou o Expedia.com. Para saber sobre a melhor forma para chegar ao atrativo turístico desejado, aplicativos como city mapper. A forma de se planejar uma viagem, de organizar roteiros, contratar serviços e mesmo de se deslocar pelos destinos turísticos em muito tem se modulado pelo uso de plataformas digitais, que também influenciam a organização do mercado de viagens e turismo.

Dispositivos tecnológicos, como celulares, computadores e tablets, são utilizados como ferramentas de assessoria e facilitação de processos de organização e compartilhamento das viagens dos turistas contemporâneos. As tradicionais agências off-line não são mais as únicas intermediárias no campo do turismo e, em muitos os casos, praticamente não há a interferência de intermediários nesses processos. O turista contemporâneo, em geral, é bastante ativo e com o auxílio dos aparatos tecnológicos muito presentes em seu cotidiano, podem personalizar ao máximo as suas viagens.

O modo como a economia se organiza tanto gera efeitos quanto é afetado pelas formas como os viajantes se comportam, por suas motivações e em como eles se relacionam com os outros indivíduos e com os objetos. As pessoas não são iguais, elas se diferem em relação a suas atitudes, percepções, motivações e imagens de crenças, e impressões sobre produtos e destinos turísticos, como ressalta Cooper et al. (2007). Portanto, ao tratá-las como iguais, com ofertas padronizadas na lógica do turismo moderno de massa, as empresas e destinos turísticos podem perder a capacidade de atração dessa demanda que é heterogênea e plural.

Essas diferenças também se associam ao hibridismo desses sujeitos com os objetos, com o meio e com as tecnologias que utilizam e de suas articulações em redes com diversos outros atores. "Não existe um único olhar do turista enquanto tal. Ele varia de acordo com a sociedade, o grupo social e o período histórico. Tais olhares são construídos por meio da diferença" (URRY, 2001, p. 16). O agenciamento não é, portanto, compreendido apenas pelo indivíduo isoladamente, mas pelo coletivo, englobando os objetos acoplados a ele, como Latour (2013) defende. 
Uma alternativa encontrada por muitos gestores do turismo para conseguir satisfazer essa demanda foi a segmentação dos produtos e serviços. Essa é uma das estratégias de marketing adotadas para otimizar o setor e gerar lucro dividindo o mercado de acordo com as características da população, como Lage (1992) ressalta. Aspectos geográficos, demográficos, econômicos e sociais dos turistas foram então sendo tratados separadamente por agências de viagens, operadoras, hotéis, cruzeiros e até mesmo pelos próprios turistas, que buscam satisfazer suas necessidades por meio do consumo de produtos e serviços elaborados para um público de características semelhantes às deles. Nessas divisões estão o turismo cultural, o de aventura, o de negócios, de saúde, o ecoturismo, entre vários outros segmentos que também se subsegmentam sempre que o mercado percebe novas oportunidades.

Também são divididos os turistas em tipologias, baseadas em seus comportamentos. Cohen (1972) os classifica em turista organizado de massas, que prefere consumir os pacotes de viagem e que mantém pouco contato com a população local; turista individual de massas, que se assemelha ao anterior, porém, aliando mais escolhas pessoais; o explorador, que organiza suas viagens de forma independente, e o andarilho, que busca se aproximar bastante da cultura local e que dispensa o consumo por empresas turísticas.

Já Plog (1974 apud MACINTOSH; GUPTA, 1993) criou as seguintes nomenclaturas para classificar os turistas em grupos psicográficos. Os ditos alocêntricos são aqueles que preferem visitar destinos pouco conhecidos e com infraestrutura ainda escassa. Eles priorizam o alto grau de interação com a população local e não utilizam serviços de agências e operadoras de viagens. No outro extremo estão os psicocêntricos. Esses turistas só viajam para lugares que possuem infraestrutura turística, utilizam largamente os serviços de empresas intermediárias e são adeptos do turismo de massa, pouco interagindo com a população local. Entre essas tipologias estão os turistas mesocêntricos, que preferem usufruir de alguns equipamentos turísticos estruturados, porém, preocupando-se em se aproximar dos aspectos culturais da localidade de destino. Plog (1974) acredita que estes são os turistas mais comuns entre todas as tipologias.

Essas classificações e divisões recorrentes no mercado e na academia contribuem para as práticas de gerenciamento das empresas e para a ampliação e qualificação da oferta aos turistas que buscam novos modos de viajar. Contudo, essas ações ainda delimitam muitas fronteiras e desconsideram as variações e convergências características de um sistema complexo.

O turismo cultural, por exemplo, é um segmento que, segundo a Secretaria Nacional de Políticas de Turismo (2006), vinculada ao Ministério do Turismo, inclui as "atividades turísticas relacionadas à vivência do conjunto de elementos significativos do patrimônio histórico e cultural e dos eventos culturais, valorizando e promovendo os bens materiais e imateriais da cultura”. No entanto, toda prática turística se associa a experiências culturais, algumas com maior, outras com menor intensidade. Todos os segmentos estariam, por definição, englobados ao turismo cultural. O ecoturismo, que prega o uso sustentável do ambiente e de seu patrimônio natural e cultural, também está associado ao turismo cultural. Ele poderia ser, ainda, praticado juntamente com atividades de aventura ou estar inserido em práticas de negócios. Esses são alguns dos inúmeros cruzamentos existentes no campo do turismo e que se transformam a todo momento.

Diante desse caráter essencialmente dinâmico do mercado de turismo, os modos de gestão e estruturação dos empreendimentos também têm se pluralizado. O uso crescente da Internet incentivou empresas a promoverem e venderem seus produtos e serviços on-line. Algumas agências mantêm seu funcionamento praticamente todo no meio digital, são as denominadas on-line travel agencies. Essas empresas de distribuição precisaram se adaptar às mudanças sociais que ocorreram em função do uso da Internet para não perderem seus clientes. 
Algumas micro, pequenas e médias empresas, para fortalecerem sua competitividade, se organizam em estruturas conhecidas como arranjos produtivos locais para desenvolverem ações coletivamente, entre empresas, instituições de ensino, financeiras e governo local (VIEIRA et al., 2013). Esse tipo de organização em rede é comum em iniciativas de turismo comunitário, em que comunidades se associam e controlam suas terras e atividades econômicas para exploração da atividade turística (CORIOLANO, 2006).

Outro movimento semelhante que se fortalece na contemporaneidade é o baseado em práticas colaborativas, porém, não só entre organizações, mas também entre os próprios consumidores. Balizado nos preceitos da economia colaborativa e solidária, que tem se fortalecido internacionalmente, preconiza o compartilhamento do consumo, as trocas de bens e serviços mesmo sem incluir valores monetários e a produção coletiva. Gansky (2011) se refere a esse modelo como Mesh e ressalta sua interferência em nossas vidas e em nossas relações com os bens e os serviços. Ele está acompanhado por um movimento de resistência ao consumo que, segundo Fournier (1998), pode variar entre evitar o mercado, minimizá-lo ou boicotá-lo. Dessa forma, anfitriões oferecem suas residências para receber turistas de forma gratuita ou em troca de serviços, como cuidar do seu animal de estimação, por exemplo.

Iniciativas como essas reforçam a ideia de que as articulações entre os atores do sistema de turismo têm se transformado substancialmente, associadas aos modelos econômicos, políticos e sociais que estão em voga na contemporaneidade. Diferentes formas de consumir as viagens se configuram, em muito potencializadas pelas novas tecnologias de comunicação e informação que se desenvolvem. Porém, identificar e analisar esses agenciamentos coletivos em um sistema complexo, que é o do turismo, é um desafio constante para os pesquisadores. Por essa razão, diferentes caminhos metodológicos precisam ser traçados e discutidos a fim de contribuir para suprir algumas das lacunas existentes em pesquisas científicas sobre o campo.

\section{DESAFIOS METODOLÓGICOS E EPISTEMOLÓGICOS}

As pesquisas científicas sobre o turismo são relativamente recentes, se comparadas às de outras disciplinas. Os primeiros estudos registrados são da virada do século XIX, desenvolvidos na Europa, segundo Lohmann e Panosso Netto (2016). Ainda de acordo com os autores, as pesquisas na área se intensificaram no século XX, porém, esse crescimento foi interrompido no período da II Guerra Mundial. No Brasil, esses estudos somente se fortaleceram nas últimas décadas, muito em razão da criação de cursos de graduação na área.

Essa escassez de investigações no campo do turismo evidencia os muitos desafios enfrentados na definição de procedimentos epistemológicos e metodológicos que sejam capazes de abarcar toda a complexidade dos objetos estudados. Muitos desses desafios estão relacionados à dificuldade de se conceituar questões tão complexas quanto o próprio termo turismo, suas medições e seu caráter.

Goeldner, Ritchie e McIntosh (2002) acreditam que as definições do termo devem englobar o turista, a empresa, o governo e a comunidade anfitriã como elementos fundamentais e o definem como "a soma de fenômenos e relações originados da interação de turistas, empresas, governos locais e comunidades anfitriãs, no processo de atrair e receber turistas ou visitantes". Já Andrade (1998) acredita que as discussões sobre o termo devem sempre incluir os componentes homem, espaço e tempo. 
Muitos teóricos foram então se dedicando a conceituar esse fenômeno, porém, ainda há muitas divergências que dificultam a sua análise. Para muitos casos é usada a conceituação da Organização Mundial do Turismo, que entende que o turismo "compreende as atividades que realizam as pessoas durante suas viagens e estadas em lugares diferentes de seu entorno habitual, por um período consecutivo inferior a um ano, com finalidade de lazer, negócios entre outras" (SANCHO, 2001, p. 38).

Outra discussão concernente ao campo é sobre o seu caráter científico. Muitos autores divergem sobre o fato de o turismo ser uma disciplina, uma ciência ou um campo de estudos. Entre os argumentos apontados para não definir o turismo como ciência, está o fato de que não há ainda um corpo teórico conceitual e metodologias próprias suficientes que elevem o turismo a esse patamar, como Boullón (2002) acredita.

O campo vem sendo estudado então a partir de metodologias e teorias de outros campos do saber, pois as relações entre o turismo e outras disciplinas são diversas. Os objetos precisam ser investigados sob distintas perspectivas e, por essa razão, a abordagem multi, inter e transdisciplinar é defendida por muitos pesquisadores do campo. Regis (2006) defende que os sistemas complexos são transdisciplinares por excelência. Para a autora, a transdisciplinaridade "surge da tentativa de se pensar para além dos limites das ciências. Parte do pressuposto de que o real é hipercomplexo, não redutível aos métodos deterministas e reducionistas da ciência clássica" (REGIS, 2006, p. 162). Ela está entre disciplinas, é a mais profunda integração que pode existir entre disciplinas, de acordo com Lohmann e Panosso Netto (2016).

No entanto, adotar a transdisciplinaridade nos estudos em turismo exige um esforço muito grande e ainda não se trata de uma realidade em grande parte das investigações. Os pesquisadores Jafar Jafari e Ritchie, apesar de a considerarem como tipo de abordagem ideal para os estudos do turismo, reconhecem as limitações, como os custos, a integração entre professores e a dedicação de alunos, e, portanto, sugerem a interdisciplinaridade como forma viável de pesquisa (LOHMANN; PANOSSO NETTO, 2016).

Os desafios também concernem à formulação de teorias próprias e aos métodos de coleta e análise de dados. Assim como em muitas outras áreas do conhecimento, os estudos do turismo em muito se basearam no pensamento moderno, que busca criar conceitos que representem o objeto, como Passos, Kastrup e Escossia (2009) evidenciam. No lugar de representar o objeto, a proposta para análise de sistemas complexos é a de acompanhar o objeto sob a óptica de Latour (2013), que defende que o social não existe como algo previamente dado, mas que podemos percebê-lo seguindo seus rastros. E, para que esse método de estudo se desenvolva, é preciso analisar os processos, os agenciamentos dos objetos e a relação deles com o meio.

Dessa forma, o método da cartografia é uma das possibilidades para descrever um sistema complexo, no lugar de análises e julgamentos sobre seus componentes e interações. Para Passos, Kastrup e Escossia (2009, p. 10), tem como sentido o "acompanhamento de percursos, implicação em processos de produção, conexão de redes ou rizomas".

Abordar um campo tão multifacetado exige, porém, um esforço metodológico ainda maior. Além da descrição dos processos, é importante investigar o objeto também por meio de outros métodos e perspectivas. A etnografia, a observação participante, além de dados quantitativos, só contribuem para a cientificidade das pesquisas. E a instrumentalização dessas abordagens em muito é possibilitada pelo uso de dispositivos e softwares que contribuem para sintetizar os dados e descrever as interações entre as partes. 
Porém, ao adotar esses métodos, é também preciso considerar que toda pesquisa é intervenção e se indissocia das experiências e pontos de vista dos pesquisadores, como Passos e Barros (2009) sugerem. O que se defende aqui são pesquisas que envolvam multimetodologias, aliando dados quantitativos e qualitativos, que possibilitem uma compreensão mais aprofundada sobre o campo, pondo em questão também a neutralidade e a parcialidade do pesquisador.

\section{CAMINHOS A PERCORRER}

Apesar da discussão sobre os sistemas complexos já se estender por alguns anos, ela é ainda bastante relevante e necessária. O pensamento moderno em muito se dedicou aos processos de purificação, dividindo questões transcendentes e imanentes e desconsiderando o hibridismo entre sujeito e objeto, natureza e cultura, entre tantos outros binômios que se interconectam e que Latour (2013) ressalta.

As reflexões contemporâneas, por outro lado, apesar de dialogarem com as questões da modernidade, defendem a dissolução de fronteiras e determinismos que ainda são bastante difundidos na atualidade. Pensar o turismo à luz da complexidade é, portanto, discutir sobre a sua imprevisibilidade, criatividade e historicidade. E essa é ainda uma perspectiva pouco trabalhada no campo.

Os desafios para compreender esses rastros são muitos. Além das questões metodológicas e epistemológicas, há limitações variadas de investimentos em pesquisas, de diálogos entre os estudos de países e regiões distintas e até mesmo a necessidade de se tratar o assunto com mais seriedade. Há de se posicionar o turismo como prática social que gera efeitos positivos e negativos em variadas dimensões e que, por essa razão, não deve ser gerido e estudado de modo isolado.

O caráter móvel dos indivíduos se intensifica rapidamente na contemporaneidade, em muito impulsionado pelo uso das novas tecnologias de informação e comunicação, conforme Sheller e Urry (2006) apontam. Os modos de viajar, de se apropriar dos territórios e de compartilhar as experiências das viagens se pluralizaram muito em razão das interações entre os processos comunicativos que ocorrem em meios on-line e off-line. E as transitoriedades e os fluxos se difundem muito rapidamente, de variadas formas.

Nesse contexto, a busca por novas metodologias de coleta e interpretação dos dados se coloca como uma das árduas tarefas para os pesquisadores do turismo. Pensar em como esses movimentos se relacionam com outras questões políticas, econômicas, culturais e tecnológicas a partir de uma abordagem transdisciplinar e transnacional pode ser um desejo ainda pouco viável, porém, fundamental para o desenvolvimento científico sobre o turismo.

\section{REFERÊNCIAS}

ANDRADE, J. V. de. Turismo: fundamentos e dimensões. 8. ed. São Paulo: Ática, 2000.

BARBOSA, Y. M. História das viagens e do turismo. São Paulo: Aleph, 2002 (Coleção ABC do Turismo). 
BARRETTO, M. Manual de iniciação ao Turismo. 10. ed. Campinas: São Paulo, 2004.

BENI, M. Análise Estrutural do Turismo. 11. ed. São Paulo: Senac, 2001.

BOULLON, R. Planejamento do espaço turístico. Bauru: Educs, 2002.

BRASIL. Ministério do Turismo. Segmentação do Turismo: marcos conceituais. Brasília: Ministério do Turismo, 2006.

COOPER, C. et al. Turismo: princípios e práticas. 3. ed. Porto Alegre: Bookman, 2007.

CORIOLANO, L. N. M. T. 0 turismo nos discursos, nas políticas e no combate à pobreza. São Paulo: Annablume, 2006.

DELEUZE, G.; GUATTARI, F. Mil Platôs: capitalismo e esquizofrenia, v. 4, Rio de Janeiro, Editora 34, p. 43, 1997.

EL PAIS. Airbnb: “el ayuntamiento prefiere el conflicto ante el acuerdo”. Disponivel em: 〈https:// elpais.com/ccaa/2017/05/09/catalunya/1494342628_146451.html. Acesso em: 25 ago. 2017.

FOLHA DE SÃO PAULO. Hackers trancam portas de quarto de hotel na Áustria e pedem resgate. Disponivel em: 〈http://www1.folha.uol.com.br/mercado/2017/02/1854722-hackers-trancam-portasde-quarto-de-hotel-e-na-austria-e-pedem-resgate.shtml>. Acesso em: 25 ago. 2017.

FOURNIER, S. Consumer resistance: societal motivations, consumer manifestations, and implications in the marketing domain. Advances in Consumer Research, v. 25, p. 88-90, 1998.

GANSKY, L. Mesh: porque o futuro dos negócios é compartilhar. Rio de Janeiro: Alta Books, 2011.

GOELDNER, C.; MCINTOSH, R.; RITCHIE, B. Turismo: princípios, práticas e filosofias. 8. ed. Porto Alegre: Bookman, 2002.

JENKINS, C.; LICKORISH, L. Introdução ao Turismo. Rio de Janeiro: Campus, 2000.

JORGE, C. G. Economia partilhada e consumo colaborativo com quem? Como a presença do Airbnb afeta os preços dos imóveis residenciais em Lisboa e no Rio de Janeiro. Dissertação (Mestrado) Universidade de Lisboa. Instituto Superior de Economia e Gestão, 2017.

LAGE, B. H. G. Segmentação do mercado turístico. Turismo em Análise. São Paulo, v. 3, n. 2, p. 61-74, 1992.

LASH, S.; URRY, J. The End of Organized Capitalism. Madison: University of Wisconsin Press. 1987.

LATOUR, B. Jamais fomos modernos. São Paulo: Editora 34, 2013.

LOHMANN, G.; PANOSSO NETTO, A. Tourism Theory: concepts, models and systems. Griffith University, Australia, Panosso Netto, University of São Paulo, Brazil. Wallingford, Oxfordshire, UK: CAB International, 2016.

OLIVEIRA, L. A. Biontes, Bioides e Borgues. In: NOVAES, A. 0 Homem-Máquina. A ciência manipula o corpo. São Paulo: Companhia das Letras, 2003.

PASSOS, E.; KASTRUP, V.; ESCÓSSIA, L. Pistas do método da cartografia: pesquisa-intervenção e produção de subjetividade. Porto Alegre: Sulina, 2009.

PRIGOGINE, I.; STENGERS, I. A nova aliança: metamorfose da ciência. Brasília: Universidade de Brasília, 1997. 
REGIS, F. Comunicação, sistemas complexos e transdisciplinaridade: um comunicar intercientífico. Contracampo, n. 15, 2006.

ROLNIK, R. Aluguéis caros e despejos: a nova crise habitacional em Lisboa e Barcelona. Blog da Raquel Rolnik. Diponivel em: 〈https://raquelrolnik.wordpress.com/2017/06/28/alugueis-caros-edespejos-a-nova-crise-habitacional-em-lisboa-e-barcelona/>. Acesso em: 22 jan. 2018.

SANCHO, A. Introdução ao Turismo. São Paulo: Roca, 2001.

SHELLER, M.; URRY, J. The new mobilities paradigm. Environment and Planning A, v. 38, 2006, p. 207220.

SIMONDON, G. L'individuation à la lumière des notions de forme et d'information. Paris: Édition Jérôme Millon, 2005.

TOURAINE, A. Crítica da Modernidade. 6. ed. Petrópolis: Vozes, 1994.

URRY, J. O Olhar do Turista. 3. ed. Editora Studio Nobel/Sesc: São Paulo. 2001.

VAZ, P. A história: da experiência de determinação à abertura tecnológica. In: D’AMARAL, M. T. Contemporaneidade e Novas Tecnologias. Rio de Janeiro: Editora Sette Letras, 1996.

VIEIRA, A. M. et al. Diretrizes para o desenvolvimento coletivo de melhoria contínua em arranjos produtivos locais. Gestão da Produção, São Carlos, v. 20, n. 2, p. 469-480, 2013. 